\title{
Study on the Motivations and Ways of Guiding Vocabulary Teaching for Teaching Chinese as a Foreign Language by Using Semantic Field Theory
}

\author{
Li Zhang \\ Xi’an Fanyi University, Xi’an, Shaanxi, 710105
}

\author{
Keywords: Teaching, Semantic Field Theory, Foreign Language
}

\begin{abstract}
Vocabulary on behalf of people around everything in the classification, classification and naming, which is the nature of the vocabulary system. Fu Huaiqing in Modern Chinese Vocabulary, the systematicness of the vocabulary is demonstrated from three aspects of the same family of words, cognate words and words in structure. Lin Xingguang thinks that dissipative structure is a system type and the vocabulary is dissipative structure, so vocabulary is equally systematic. By the 1980s, scholars reached a consensus that the vocabulary is systematic and the Chinese vocabulary is not disorganized. The systematicness of the meaning of the words is an objective reality.
\end{abstract}

\section{Introduction}

Vocabulary is the convergence of words and fixed phrases, but such convergence is not chaotic, arbitrary, or accidental piling up, but rather systematic clustering. In different languages, the composition of the vocabulary and the relationship between the ingredients may be very different, which determines their different vocabulary appearance. Is the same language, in its different periods, the vocabulary components and their relationship will not be exactly the same, thus forming a different vocabulary system. The systematic expression of vocabulary is the difference in the combination of words and meaning without words. Language is a convention, the word is a combination of sound and meaning, the relationship between the sound and meaning of the word is arbitrary, a semantic and what kind of speech into words, each language has its own agreement. For example, the meaning of "advanced animal who can work, speak, stand upright" is combined with the sound of "ren" in modern Chinese to form the word "human", which is also systematically expressed in terms of ['hju: mən] Languages are often different language units to express a concept. A concept is represented by a word in the A language and a phrase in the B language. For example, "Communist" in Chinese is "communist party" in English; "actor" in Chinese is "actor" in English "Brother" in Chinese is "elder brother" in English; "brother" in Chinese is "younger brother" in English [3]

Chi Chang-hai in the "Introduction to Modern Linguistics" proposed word formation is divided into simple words, compound words, additional word formation, overlapping word formation and other types. Throughout the word formation of modern Chinese vocabulary, although the type of word formation seems complicated, but the most important is compound word formation. In modern Chinese vocabulary, more than $90 \%$ of the words are compound words, and most of the compound words are compound compound words. For a flexible and convenient word formation, clear meaning, easy to understand and a series of reasons, has become the most active, the most productive one of the word-building. Modern Chinese is rich in primes. A series of words use the same morpheme under the control of related links and categorization principles, and these same primes often have some sort of intrinsic connection under the common morpheme, forming A semantic field containing common morphemes, for example:

Reflects the genre of field: table - bed - stools belong to the furniture category; oranges - apples pears are fruits; pen - eraser - paper belong to the stationery category.

Reflect the order of the righteousness field: university - secondary school - primary school; first test - retest; assistant teacher - lecturer - associate professor - professor

Reflect the righteousness of the relationship: parents - children; teachers - students; husband wife; brother - brother 
Reflects the meaning of synonymous relations: request - plea - begging; hope - expectation hope; quiet - silence - quiet

Reflect the antonyms of the righteousness of the field: men - women; attend - absent; progress regression

\section{Conforms to the Chinese "heavy meaning light form" features}

Chinese is the language of Han nationality, and modern Chinese is the language used by modern Han nationality. Chinese is a isolated language, which requires a specific context to express, not an external form such as the change of lexical items like English. It is precisely because of the Chinese language has such a heavy light of the characteristics of the form, requiring us to vocabulary teaching in foreign Chinese, full attention to the role of context and semantics, focusing on developing students' sense of language.

The company is located in:

The reason why the semantic field theory can guide the vocabulary teaching of Chinese as a foreign language is that it advocates that the unity of the language system and the influence of the context on the meaning should be emphasized with the connection and development viewpoint. A lot of words in a semantic field are often interrelated, can form a common topic. For example, when we go to eat, we can say that swiping a card, eating a meal, eating noodles and so on, because of the existence of context, make these words a related semantic field. In fact, to a certain extent, context and semantic field Is the same.

\section{The use of semantic field theory to guide foreign language teaching methods}

Semantic field theory is used by many scholars to guide the teaching of Chinese as a foreign language. The importance of Chinese in light form and the systematicness of Chinese vocabulary all explain the necessity of using the semantic field theory to guide the teaching of Chinese as a foreign language. So how do we help the students to establish a vocabulary framework? I think the main points are as follows:

1 to establish generic semantic field:

Generic semantic field members belong to the same category. Such as dragon fruit, apples, pears, oranges belong to the same fruits; spoons, bowls, shovels belong to kitchen utensils.

It is worth noting that the things that are summed up in the gendered field often exceed the sum of the things listed. For example, paper and ink paper can represent all stationery, pots and pans on behalf of all kitchen utensils, tables and chairs on behalf of all the furniture, fried cooking represents all cooking practices. Things like this are often difficult to exhaust.

On the other hand, the classification of generic genus in Chinese does not necessarily correspond to the classification of science. Many categories are based on people's certain thoughts and habits. For example, "poultry" and "wild birds", "pests" and "beneficial insects" are only categories in which people are classified according to their relationship with one another. "Sensual" only refers to the aristocratic martyrdom of life.

Therefore, in the process of teaching Chinese as a foreign language, we should better teach the students the common-sense words of the table so as to facilitate them to set up a large class so that students can classify them later when they study the members of the relevant righteousness field. Easy to form a system. If there is no word of "color" in the new words in the textbook, we take the initiative to help students summarize the word "color" when teaching students to red, yellow, blue, green and purple.

The order of the members of the field of order in accordance with a certain order, such as "spring - summer - autumn - winter", "first test - retest", "university - secondary - primary", "first volt - two volts - three volts". If the meaning of the field contains many members, often with numerals to indicate, such as junior high school there are "one - two - three ......"

Some of the sequence of etiquette can also be repeated, called "recycling righteousness," such as "Monday - Tuesday - Wednesday ... .. Sunday", "January - February - March - .... month" 
In the teaching of Chinese as a foreign language, the sequence of meaning and the genre of genre can help students to expand their vocabulary, construct the vocabulary network system, activate the classroom atmosphere, train their divergent thinking and enhance their enthusiasm and initiative in learning. If teachers can combine the theory of sequence of eloquence to explain this aspect, it will not only help students to deepen their memory, but also enable students to have a deeper understanding of Chinese and stimulate students' interest in learning.

The two words are antagonistic to each other in the sense of being, but they depend on each other in the sense that they are premised on the existence of each other. For example, "south" is for "north", "teacher" is for "student", and "teaching" is for "learning" and vice versa. No such is true. This, both interdependent. According to the meaning can be divided into three categories: 1, table time and direction: North-South; East-West; Northeast; Southwest; East-West Northwest; before and after; about; up and down; past, future 2, interpersonal relationships: teacher - student; landlord - tenant; husband - Wife; mother-in-law - daughter-in-law 3, table activities: teaching - learning; income - hair; pay - then; to - to; wear - pick; wear - off;

Often there are only two relations of righteousness. In the teaching of Chinese as a foreign language, two words in the same relationship field often appear together, forming a related topic together. However, when such synonyms appear at the same time, students can easily grasp the relationship between each other. Such as "buy - sell" consonants and vowels are the same, only the tone is different, in form, the two are very similar, so students can know that is a set of corresponding words, but there is no way to distinguish between the two can not be correct use. Another example is "borrow - also" Although the pronunciation and the form of no similarities, but in the direction of the students will not figure out, how is "borrowed", who gave who called "also." In this regard, teachers need to devote some effort to helping students understand and adopt appropriate body language when appropriate to help students to deepen their impression.

Semantic fields composed of words of the same or similar meanings are called synonymous fields, and each word in the synonymous field is called a synonym. The same meaning field has two kinds of situations: The first kind: The synonymy, such words appear less in the vocabulary. Two terms in the synonymous terms, no matter from which perspective, have the same meaning and can usually be used interchangeably in the language. Such words as "speech" and "speech", "aware" and "awareness", "bicycle" and "bicycle" and so on. The second category: synonyms, this synonym exists in a large number of words, the language expression plays a very positive role. Therefore, careful analysis is needed to prevent misuse. For example, "resolute - firm," all have the idea of taking decisions and not being shaken by external forces. However, both of them have slight differences in meaning and usage, while "determined" focuses on decisiveness and "hesitation"; "firm" Focus on the position of stability, with the "shaken" the opposite. Therefore, "firm" is often used to indicate action, attitude; "firm" is often used to express position and will.

In the teaching of Chinese as a foreign language, only a few synonyms are proposed by teachers. Most synonyms are proposed by foreign students because they are deeply influenced by the vocabulary of their native speakers. Some of them are alienated in our opinion Chinese words are very confusing in their eyes. In common synonyms, there are differences in meaning or in terms of degree, scope, emotional color, differences in style, or differences in usage or collocation, so that synonyms can be differentiated into vocabulary teaching of Chinese as a foreign language A key, difficult. Therefore, in teaching, it is necessary to establish the semantic field of synonymous relationship to guide the teaching of Chinese as a foreign language.

Antonyms field is a semantic field formed by two words with opposite or opposite meanings. Two words must meet the following four conditions to constitute antisense semantic field: first, the two words have a common sense of the field. Such as "daytime" and "nighttime" all mean one day's time, "fast" and "slow" are judgments of speed. "Buy" and "sell" are both trade practices and have common sense areas. Second, the two words are from the same axis at both ends, such as "South" and "North"; "Cold" and "Hot". Third, the concept of two words constitute a contradictory relationship or oppose the relationship, that is, a non-b, that is, b non-a, such as deep must not be shallow. Fourth, the two words that constitute the field of antisense semantics must be consistent in 
style, otherwise they can not be constituted. Such as "husband" "wife" in the opposite sense, the former is a written language, the latter is a verbal language, two words can not constitute the antisense field [4].

There are two types of antisense field:

The first: complementary antisense field. In such a righteousness in the two words, affirmative a will be denied b, affirmative $b$ will be denied a; the same time, the negative a will certainly $b$, negative $b$ will affirmative a. Between the two does not allow the existence of a non-b third parties. With the graph that is:

The company is located in:

such as:

Health - dead; moving - static; yes - no; true - false

The second: polar anti-meaning field. Two words in this semantic field, affirmation a is negation $b$, affirmation $b$ is negation $a$, but negation $a$ is not necessarily affirmative $b$, negation $b$ is not necessarily affirmative a. Because there are c, d, e and other possibilities exist. With the graph that is:

such as:

White - black; big - small; light - heavy; deep - shallow

In the teaching of Chinese as a foreign language, the teaching of antonyms is also a difficult task. When facing the teaching of antonyms, teachers also need to devote more effort to helping students to establish a framework of antisense fields and gradually guide students to think on their own and cultivate their ability to build their own anti-semantic field.

Although the semantic field theory can explain the macroscopic systematicness of vocabulary, its application in vocabulary teaching of Chinese as a foreign language is still scarce. On the one hand, because of our neglect of vocabulary teaching, we focus our attention on grammar teaching; on the other hand, it is a profound and complex Chinese language. It is still a difficult problem to combine theory with practice in the teaching process. Teachers should also improve their self-cultivation and self-discipline while teaching, which is also a challenge to the traditional teaching methods.

\section{References}

[1] Fu Huai Qing. Modern Chinese Vocabulary [M]. Peking. Peking University Press, 1985

[2] Yu Yunxia. Homophone analysis [M]. Beijing: Beijing Language and Culture Institute Press, 1992

[3] Zhang Zhiyi. Vocabulary Linguistics [M]. Beijing: Commercial Press, 2001

[4] Zhou Jian. Lexical lexicology research [M]. Beijing: Commercial Press, 2004

[5] Chinese Academy of Social Sciences Institute of language dictionary editing room. Modern Chinese Dictionary [K] (Fifth Edition). Beijing: Commercial Press, 2005 